level of intensity of Tartar deposition and deep pathological periodontal pockets was found in the main group. Peaks in salivation decline or hyposalivation were more often diagnosed in patients with mental illness. When assessing the frequency of occurrence of dental anomalies (PCA), deep bite and progenia occupied the highest proportion in both groups in relation to other types of anomalies, but in the main group the frequency of occurrence of cross bite was higher $(\mathrm{p}=0.0151)$. The rate of reactive anxiety during dental interventions in the main group was $50.1 \pm 0.72 \%$, compared to $31.6 \pm 0.57(\mathrm{p}<0.001)$ in the control group. A similar pattern was observed when assessing the level of personal anxiety in the subjects.

The conducted clinical study and the results of the questionnaire show that the values of the high level of reactive anxiety in mentally ill and practically healthy individuals at the stages of treatment are markedly different. Taking into account the fact of the negative influence of somatic pathologies on the functional state of saliva, some of its structural parameters, including fluctuations in the $\mathrm{pH}$ of the oral fluid, were studied. In our studies in the control group, the $\mathrm{pH}$ value was recorded within the normal range. In the main group, the $\mathrm{pH}$ of the oral fluid was lower and there was a pronounced shift in the $\mathrm{pH}$ of saliva to the acidic side- $6.11 \pm 0.030$ versus $7.02 \pm 0.041$ in the control group $(p<0.001)$. Thus, the presence of mental disorders and taking potent drugs leads to serious disturbances in the acid-alkaline balance of the oral cavity and its shift to the acidic side.

Conclusion. The results of the studies indicate a high level of incidence of inflammatory and destructive diseases of periodontal tissues and hard tissues of teeth in the main group of persons with mental disorders. The presence of the studied somatic pathology negatively affects the state of acid-base balance of saliva with its shift to the acidic side-and the frequency of development of dental anomalies. Key words: mental illness, dental caries, periodontitis, saliva, anomalies.

$$
* * *
$$

1. Kumar A., Kardkal A., Debnath S., Lakshminarayan J. Association of periodontal health indicators and major depressive disorder in hospital outpatients The Journal of Indian Society of Periodontology, 2015; 19 (5): $507-511$

2. Nayak S.U., Singh R., Kota K.P. Periodontal Health among Non-Hospitalized Chronic Psychiatric Patients in Mangaluru City-IndiaJClinDiagn Res. 2016 Aug; 10(8): 40-43

3. Nayak SU, Nayak DG, Uppoor AS, Pai KK. Evaluation of cortisol levels in gingival crevicular fluid and saliva in anxious and non-anxious patients with chronic periodontitis. DentResJ. 2013;10:474-81

\title{
Salihova K.M. \\ Prevalence of different pathologies in the practice of a family doctor
}

Azerbaijan State Institute Of Improvement Of Doctors named after A. Aliyev

(Azerbaijan, Baku)

doi:10.18411/sciencepublic-15-11-2019-10

idsp: sciencepublic-15-11-2019-10

General practitioner (family doctor) - a specialist who has training in related specialties and is able to provide multidisciplinary outpatient care for the most common diseases and emergencies. Ophthalmology is one of the areas of medicine responsible for the prevention, diagnosis and treatment of eye diseases. [1,2]

The incidence of myopia in the Nenets Autonomous district exceeds the average Russian level by 4 times, in the Chukchi Autonomous district-by 2 times, in the republics of Komi, Chuvashia, Altai, Sakha (Yakutia), Udmurtia, Mari El, Bashkortostan, Krasnoyarsk Krai, Kurgan region - by 1.5 times. At the same time, in the Chechen Republic, myopia is detected 2.5 times less often than in Russia as a whole.

The incidence of glaucoma, exceeding the national average by 2 times, was noted in the Ivanovo region, St. Petersburg, 1.5 times - in the Republic of Sakha (Yakutia), Kurgan, Kirov, Omsk regions, Nenets Autonomous district. 
The indicator of blindness and low vision in the whole of the Russian Federation increased by $3 \%$, while in the Pskov region there was a sharp increase in the indicator (7 times). The highest level of blindness and low vision is registered in the Altai Republic (10 times higher than the national average). Blindness and low vision are 2-3 times more common in the Voronezh, Omsk regions, Nenets Autonomous Okrug, the republics of Dagestan, Bashkortostan, North Ossetia-Alania. At the same time, there was a sharp decrease in the number of patients with blindness and low vision in the Republic of Ingushetia - 2.5 times, Karachay-Cherkess Republic - 2.7.

The incidence rate of ophthalmopathology among children in Russia was 13,242. 5, which is $3 \%$ higher than in 2011. The maximum level of morbidity among children (more than 2 times higher than the national average) was observed in the Nenets, Yamalo-Nenets Autonomous Okrug, Kurgan, Arkhangelsk, Murmansk regions, in St. Petersburg. The incidence is 3 times lower than the average in Russia, registered in Kabardino-Balkaria, Karachay-Cherkess, Chechen republics, Jewish Autonomous region, Lipetsk and Sakhalin regions.

In the structure of diseases of the eye and appendage among children, as well as among adults, myopia leads-34\% (2.1 million cases, 4501.2 per 100 thousand children), conjunctivitis-16.6\%, astigmatism-10\%. Blindness and low vision from different causes among children in Russia are 29.3 thousand cases (110.0 per 100 thousand children).[3]

Purpose of research. To determine the level and nosological structure of the General morbidity of the population with diseases of the visual organs based on the materials of the circulation.

Materials and methods of research. The scope of observation was established by the continuous coverage of all units of observation in polyclinics (№3; 16; 17; 10; 5) Yasamal district of Baku, Azerbaijan Republic (total 25308 diagnoses, including 12759 diagnoses in men, 12549 diagnoses in women).

The dependence of the level of General morbidity on age was estimated on the basis of studying the variability of the morbidity index $(\mathrm{y})$ with the sequence number of age (x) groups (0-4 years- 1 ; 5-9 years- 2 ; 10-14 years-3; 15-19 years- 4 ; 20-29 years-5; 30-39 years-6; 40-49 years-7; 50-59 years- 8 ; 60-69 years-9; 70 years and older-10).

The results obtained and their discussion. The level of total incidence of diseases of the visual organs was $109,1 \pm 0,7 \%$ o $(107,7-110,5 \%)$; the values of the indicator in the group of men $(114,3 \pm 1,0 \% ; ; 112,3-116,3 \%)$ and women $(104,3 \pm 0,9 \% ; 102,5-106,1 \%)$ they differed significantly from each other $(\mathrm{P}<0.05)$, and the risk of General morbidity was relatively higher in the group of men (relative risk 1.1; attributive risk 10.0).

The frequency of diseases of the visual organs in the first place are diseases of the muscles of the eye, disorders of eye movement, accommodation and refraction (ICD-10 codes: N49-N52); per 1000 population accounts for 52.0 0.5 cases of pathology of the noted category $(51.0-53.0 \%)$. The level of General morbidity in men $(54,7 \pm 0,7 \%$; $53,3-56,4 \%$ o $)$ and female $(49,4 \pm 0,6 \% ; 42,8-50,6 \%)$ populations differ significantly from each other. The risk of General morbidity in the male population compared to the female population is greater. Among the diseases of the visual organs, the second place is occupied by diseases of the lens (ICD codes: H25 - H28); $15.3 \pm 0.3$ cases $(14.7-15.9 \%)$ of these pathologies per 1000 of the total population. In terms of the overall incidence of diseases of the lens male $(14,5 \pm 0,4 \% ; 13,7-15,3 \%)$ and female $(16,1 \pm 0,4 ; 15,3-16,9 \%$ o $)$ the population is significantly different from each other $(\mathrm{P}<0.05)$, and the risk of morbidity is relatively higher among the female population (relative risk 1.11; attributive risk 1.6\%).

The third place in the structure of the total incidence of diseases of the visual organs is occupied by conjunctival diseases (ICD codes: N10 - N13); per 1000 population there are $14.1 \pm 0.2$ cases of conjunctival pathology (13.7 -14.5\%). In terms of the overall incidence of conjunctival diseases the difference between male $(14,7 \pm 0,4 \%$; $13,9-15,5 \%$ ) and female 
$(13,5 \pm 0,3 \% ; 12,9-14,1 \%)$ the risk of General morbidity is greater among men compared to women (relative risk 1.09; attributive risk 1.2\%o).

Glaucoma (ICD codes: H40 - H42) ranks fourth among the cases of total incidence of diseases of the visual organs, per 1000 population there are $8.2 \pm 0.2$ cases of glaucoma. The overall incidence of glaucoma in the male $(10.0 \pm 0.3)$ and female $(6.5 \pm 0.2)$ populations differs significantly from each other.

The fifth place in the structure of the total incidence of diseases of the visual organs is occupied by diseases of the eyelids (ICD-10 codes: N00-N03). The overall incidence of eyelid disease was $5.1 \pm 0.2 \%$ for the entire population, $5.7 \pm 0.2 \%$ for the male population, and $4.6 \pm 0.2 \%$ for the female population. Visual disorders and blindness (ICD-10 codes: H53 H54) occupy the sixth place in the structure of the total incidence of diseases of the visual organs of the population. The level of General morbidity of the population with visual disorders and blindness was $4.1 \pm 0.1 \%$. The value of this indicator does not differ significantly in the male $(4.3 \pm 0.2)$ and female $(4.0 \pm 0.2)$ populations.

Diseases of the choroid and retina (ICD-10 codes: H30 - H36) occupy the seventh place in the structure of the total incidence of visual pathologies; per 1000 population accounts for $3.2 \pm 0.1$ cases of these pathologies (3.0-3.6\%). The value of the indicator in the male and female populations was the same $(3.2 \pm 0.2 \%$ ).

Iridocyclitis and other diseases of the iris and ciliary body (ICD-10 codes: H20 - H21) occupy the eighth place in the structure of the total incidence of diseases of the visual organs, the level of total incidence of these pathologies was $1.8 \pm 0.1 \%$ for the entire population, $2.0 \pm 0.1 \%$ for the male population, $1.5 \pm 0.1$

Keratitis, scarring, corneal opacity and other diseases of the cornea (ICD code:H16 H18) occupy the ninth place in the structure of the total incidence of diseases of the visual organs. The level of General morbidity of these pathologies had no gender differences, per 1000 population there were $1.7 \pm 0.1$ cases of diseases $(1.5-1.9 \%)$.

Diseases of the lacrimal apparatus occupy the tenth place in the structure of the General morbidity of the population with pathologies of the visual organs. The overall incidence rate was $1.3 \pm 0.1 \%$ for the entire population, $1.0 \pm 0.1 \%$ for the male population, and $1.5 \pm 0.1 \%$ for the female population.

Diseases of the vitreous body and the eyeball (ICD-10 code: N43-N45) occupy the eleventh place in the structure of the overall incidence of ocular pathologies; the incidence rate in the male and female populations is the same $(1,0 \pm 0,1 \% ; 0,8-1,2 \%)$.

Thus, the incidence of diseases of the visual organs has gender characteristics (the overall incidence rate is higher among men), the structure of the incidence is dominated by disorders of accommodation and refraction $(52,0 \pm 0,5)$, lens disease $(15,3 \pm 0,3)$, conjunctiva $(14,1 \pm 0,2)$, glaucoma $(8,2 \pm 0,2)$. The gender difference is typical for the incidence of disorders of accommodation and refraction (the risk is greater among men), glaucoma (the risk is greater among men), diseases of the lens (the risk is greater among women) and other pathologies.

Conclusion. The General morbidity of the population with ocular pathologies is low in terms of appeal, which indicates the need for active use of primary health care resources to identify these pathologies. Therefore, it is necessary to use the potential of family medicine for the early detection of eye diseases.

$$
* * *
$$

1. Eye diseases in the practice of the family doctor: a textbook for students. Institute of postgraduate education (General practitioners / family doctors) / Comp. Grigorovich M. S., Vychugzhanina E. Yu., Abramova T. V., Kudryavtseva Yu. V., Rudakova E. V.-Kirov: Kirov state medical Academy, 2009: 113. [in Russian]

2. Zhdanova L. V. Syndrome of "red eye" in the practice of a family doctor . New St. Petersburg medical records. 2009; 2:77-80. [in Russian] 
3. Neroev V. V. Organization of ophthalmological care to the population of the Russian Federation. Journal of ophthalmology. 2014; 130(6): 8-12[in Russian] 